\title{
Valence of manganese, in a new oxybromide compound, determined by means of electron energy loss spectroscopy
}

\author{
J.L. Mansot $\left({ }^{1}\right)$, P. Leone $\left({ }^{2}\right)$, P. Euzen $\left({ }^{2}\right)$ and P. Palvadeau $\left({ }^{2}\right)$ \\ ( $\left.{ }^{1}\right)$ Laboratoire de Physique Cristalline, Institut des Matériaux de Nantes, 2 rue de la Houssinière, \\ 44072 Nantes cedex 03, France \\ $\left(^{2}\right)$ Laboratoire de Chimie du Solide, Institut des Matériaux de Nantes, 2 rue de la Houssinière, \\ 44072 Nantes cedex 03, France
}

(Received October 28, 1993; accepted April 25, 1994)

\begin{abstract}
Electron Energy Loss Spectroscopy, at $\mathrm{Mn} M_{2,3}$ and $L_{2,3}$ edges is used in order to investigate the ionization state of manganese in a new oxybromide compound. The experimental procedure and the various approaches used to determine Mn oxidation state (edge energy shifts and $L_{3} / L_{2}$ ratios) are tested on a wellknown manganese oxychloride containing $\mathrm{Mn}^{2+}$ and $\mathrm{Mn}^{3+}$ cations. The comparison of the respective confidence limits of each approach shows that the best precision is obtained with the method based on the energy shifts of the Mn $L_{2,3}$ edges. That experimental approach applied to the manganese oxybromide allows us to confirm that $\mathrm{Mn}^{4+}$ is present in this new compound and a reconstruction of the $L_{2,3}$ white lines, using normalized standard spectra, seems to show the presence of three Mn oxidation states in the material.
\end{abstract}

\section{Introduction.}

The reaction between manganese dioxide and manganese dibromide in the temperature range 300 and $500^{\circ}$ in a sealed Pyrex tube [1], leads to a new manganese oxybromide whose formula is $\mathrm{Mn}_{7.5} \mathrm{O}_{10-\delta} \mathrm{Br}_{3}$.

In this product, manganese atoms will present various valence states. Three hypotheses are proposed:

$$
\mathrm{Mn}^{4+} \mathrm{Mn}_{6}^{3+} \mathrm{Mn}_{0.5}^{2+} \mathrm{O}_{10} \mathrm{Br}_{3}, \quad \mathrm{Mn}_{0.5}^{4+} \mathrm{Mn}_{7}^{3+} \mathrm{O}_{10} \mathrm{Br}_{3}, \quad \mathrm{Mn}_{7}^{3+} \mathrm{Mn}_{0.5}^{2+} \mathrm{O}_{9.5} \mathrm{Br}_{3} \text {. }
$$

In the last formulation oxygen vacancies are needed to conserve charge neutrality in the structure. In order to dismiss one or two of these hypotheses, Electron Energy Loss Spectroscopy (EELS) [2] is used in order to probe the oxidation state of manganese in this compound.

\section{Experimental method.}

It is established for a long time that, as in XPS, the energy position of ionisation edges for an element strongly depends on its valence state [2-4]. In the case of transition metals, the relative 
intensities of the $L_{3}$ and $L_{2}$ white lines $\left(2 \mathrm{p}^{3 / 2} \rightarrow 3 \mathrm{~d}^{3 / 2} 3 \mathrm{~d}^{5 / 2}, 2 \mathrm{p}^{1 / 2} \rightarrow 3 \mathrm{~d}^{3 / 2}\right)$ are highly sensitive to the $3 \mathrm{~d}$ occupancy [2-7].

In order to investigate the valence state of manganese in the oxybromide compound, we will benefits from these facts.

The energy position of manganese $L_{2,3}$ and $M_{2,3}$ edges will be measured in five standards presenting a well defined valence state, respectively $\mathrm{Mn}^{\mathrm{II}} \mathrm{Cl}_{2}, \mathrm{Mn}^{\mathrm{II}} \mathrm{Br}_{2}, \mathrm{Mn}^{\mathrm{II}} \mathrm{O}, \mathrm{Mn}_{2}^{\mathrm{III}} \mathrm{O}_{3}, \mathrm{Mn}^{\mathrm{IV}} \mathrm{O}_{2}$.

This will allow us to correlate the ionisation state of manganese to the position of the edge. The three standard compounds for the valence state $2+$ are used to establish the influence of the anion (especially electronegativity) on the edge position for the same formal oxidation state. In the $\mathrm{Mn}_{7.5} \mathrm{O}_{10-\delta} \mathrm{Br}_{3}$ structure, manganese atoms will be surrounded by oxygen and bromine atoms in $\mathrm{MnO}_{6}$ and $\mathrm{MnO}_{4} \mathrm{Br}_{2}$ octahedra.

In order to complete this approach, we will use also the $L_{3} / L_{2}$ white line ratio which is, as previously mentioned, strongly dependent on the $3 \mathrm{~d}$ occupancy (i.e. the oxidation state).

The validity of the method will be tested on the reference compound $\mathrm{Mn}_{8} \mathrm{O}_{10} \mathrm{Cl}_{3}$ [8] which presents two manganese oxidation states $\mathrm{Mn}_{7}^{3+} \mathrm{Mn}_{1}^{2+} \mathrm{O}_{10} \mathrm{Cl}_{3}$ which leads to a calculated mean valence state of 2.875 . In that particular case, the experimental results obtained will be compared to the theoretical one and the precision of the three different approaches will be discussed.

\section{Samples.}

3.1 PRODUCTS. - The standards compounds used are pure $\mathrm{MnBr}_{2}, \mathrm{MnCl}_{2}, \mathrm{MnO}, \mathrm{Mn}_{2} \mathrm{O}_{3}$, $\mathrm{MnO}_{2}$ (Strem Chemicals, purities $>98 \%$ ).

The reference compound, $\mathrm{Mn}_{8} \mathrm{O}_{10} \mathrm{Cl}_{3}$, used in order to test the method, and the studied oxybromide are obtained in redox reactions between the manganese dioxide and the manganese dihalide at 300 to $500^{\circ} \mathrm{C}$ in a sealed, evacuated pyrex tube [1,8]:

$$
\begin{aligned}
& 5 \mathrm{MnO}_{2}+3 \mathrm{MnCl}_{2} \rightarrow \mathrm{Mn}_{8} \mathrm{O}_{10} \mathrm{Cl}_{3}+3 / 2 \mathrm{Cl}_{2} \\
& 5 \mathrm{MnO}_{2}+5 / 2 \mathrm{MnBr}_{2} \rightarrow \mathrm{Mn}_{7.5} \mathrm{O}_{10} \mathrm{Br}_{3}+\mathrm{Br}_{2}
\end{aligned}
$$

$\mathrm{Mn}_{8} \mathrm{O}_{10} \mathrm{Cl}_{3}$ is tetragonal (space group: $\mathrm{I} / \mathrm{mmm} ; \mathrm{a}=9.275(2) \AA, \mathrm{c}=13.037(5) \AA, \mathrm{Z}=4$ ). In the structure Mn ca:-, - sre distributed on 5 sites (Fig. 1):

$-\mathrm{Mn}^{3+}$ occupy symmetric oxiáe uctahedra (Mis; and distorted mixed oxide/chloride octahedra (Mn1 and Mn2).

- $\mathrm{Mn}^{2+}$ occupy cubic oxide (Mn4) and octahedral chloride (Mn5) sites.

The manganese oxybromide, $\mathrm{Mn}_{7.5} \mathrm{O}_{10-\delta} \mathrm{Br}_{3}$, like the oxychloride, is tetragonal with parameters $a=9.327(5) \AA$ and $c=13.104(3) \AA$ but the bromine octahedra (Mn5) are empty. It implies either the presence of oxygen vacancies in the oxide network or the presence of $\mathrm{Mn}^{4+}$. In the latter case, two cationic arrangements conserving $\mathrm{c}^{\mathfrak{r}}$ arge neutrality are considered:

1) $\mathrm{Mn}_{0.5}^{4+} \mathrm{Mn}_{7}^{3+} \mathrm{O}_{10} \mathrm{Br}_{3}, \mathrm{Mn}^{4+}$ occupying oxide cubes (Mn4).

2) $\mathrm{Mn}^{4+} \mathrm{Mn}_{6}^{3+} \mathrm{Mn}_{0.5}^{2+} \mathrm{O}_{10} \mathrm{Br}_{3}, \mathrm{Mn}^{2+}$ in oxide cubes (Mn4) and $\mathrm{Mn}^{4+}$ in symmetric oxide octahedra (Mn3).

3.2 SAMPLE PREPARATION. - Two methods are used in order to prepare the sample for the EELS study.

In the case of $\mathrm{MnBr}_{2}$ and $\mathrm{MnCl}_{2}$, soluble in alcohol, one drop of a diluted solution of the dihalides in ethanol is deposited onto a holey carbon grid; after evaporation of the solvent, material stays on the carbon grid as a thin film or as thin menisci in the holes.

For the other compounds, available as powder, the samples are prepared by crushing into ethanol, dispersion by ultrasonnicating and deposition of one drop of the surnatant dispersion 


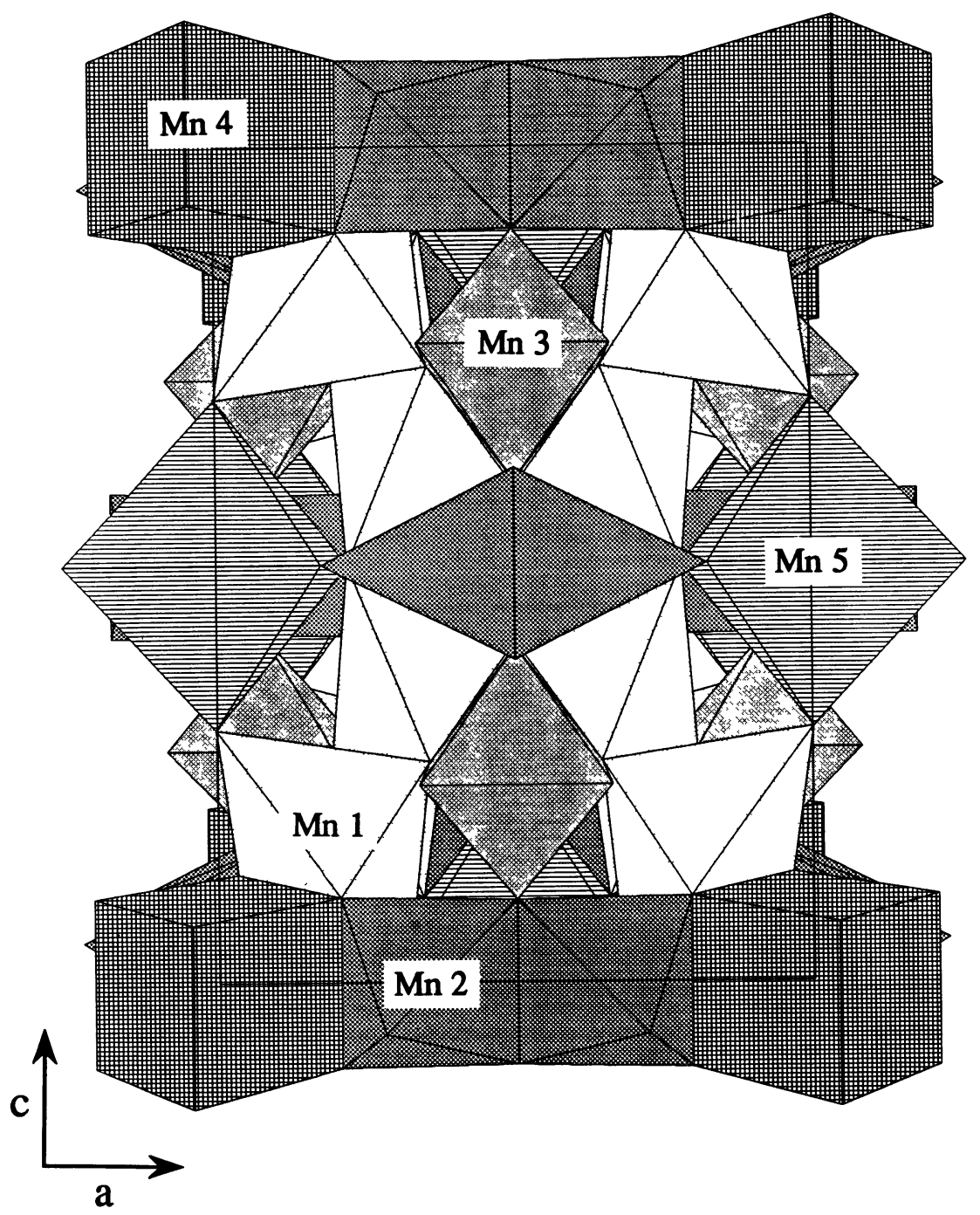

Fig. 1. - Representation of the $\mathrm{Mn}_{8} \mathrm{O}_{10} \mathrm{Cl}_{3}$ structure showing the various sites occupied by the $\mathrm{Mn}$ cations. $\mathrm{Mn} 1, \mathrm{Mn} 2$ and $\mathrm{Mn} 3$ are occupied by $\mathrm{Mn}^{3+}$, whereas $\mathrm{Mn}^{2+}$ are in the $\mathrm{Mn} 4$ and $\mathrm{Mn} 5$ sites.

onto a holey carbon grid. After solvent evaporation, the finest particles stick onto carbon grid by Van der Waals interactions.

In order to record energy shifts with a precision better than $0.2 \mathrm{eV}$, two compounds are deposited on the same grid, first the sample of interest (standards or unknown compounds) and after $\mathrm{MnCl}_{2}$ as an internal reference. The spectra are then recorded successively on the internal reference, on the studied compound and once again on the internal reference in order to check for the possibility of instability of the energy of the incident electron beam during the recording time. Such a procedure will take about 30 seconds at least and will allow us to measure energy shifts whith an experimental error estimated to be $0.1 \mathrm{eV}$ in the case of $L_{3}$ edges.

Quantitative EELS analyses are performed on the standard oxides in order to check for the presence of mixed valences in these compounds due either to purity problems or to irradiation damage (especially reduction by the electron beam). 


\section{Experimental conditions.}

Experiments were carried out on a Philips CM30 Microscope running at $150 \mathrm{kV}$ with an undersaturated $\mathrm{La} \mathrm{B}_{6}$ cathode.

The EEL spectra were recorded in the diffraction coupling mode by means of a Gatan 666 parallel spectrometer.

The condensor, objective and spectrometer entry aperture diameters were respectively $150 \mu \mathrm{m}$, $70 \mu \mathrm{m}$ and $2 \mathrm{~mm}$ leading to a collection half angle of $12 \mathrm{mrad}$ and an energy resolution of $0.9 \mathrm{eV}$ (FWHM of the zero loss peak). The EEL spectra were recorded with an energy dispersion of 0.1 $\mathrm{eV}$ per channel on areas of 1 to $5 \mu \mathrm{m}$ diameter, the total irradiation dose lying in the range 50 to $500 \mathrm{e} / \AA^{2}$ for one spectrum recording.

Table I. - Energy position of the top of the $M n L_{3}$ white line in the various compounds.

\begin{tabular}{|c|c|}
\hline compounds & $\begin{array}{c}\text { energy of the top } \\
\text { of the } \mathrm{Mn} \mathrm{L}_{3} \text { white line (eV) }\end{array}$ \\
\hline $\mathrm{MnBr}_{2}$ & $637.6(1)$ \\
\hline $\mathrm{MnCl}_{2}$ & $637.8(1)$ \\
\hline $\mathrm{MnO}$ & $637.8(1)$ \\
\hline $\mathrm{Mn}_{2} \mathrm{O}_{3}$ & $639.3(1)$ \\
\hline impure $\mathrm{MnO}_{2}\left(\mathrm{MnO}_{1.8}\right)$ & $640.1(1)$ \\
\hline $\mathrm{MnO}_{2}$ & $640.7(1)$ \\
\hline $\mathrm{Mn}_{8} \mathrm{O}_{10} \mathrm{Cl}_{3}$ & $639.1(1)$ \\
\hline $\mathrm{Mn}_{7.5} \mathrm{O}_{10} \mathrm{Br}_{3}$ & $639.4(1)$ \\
\hline
\end{tabular}

\section{Results.}

The figures 2 and 3 present the $\mathrm{Mn} L_{2,3}$ recorded on the four standards, $\mathrm{Mn}_{8} \mathrm{O}_{10} \mathrm{Cl}_{3}$ and $\mathrm{Mn}_{7.5}$ $\mathrm{O}_{10-\delta} \mathrm{Br}_{3}$, the energy shifts of the $\mathrm{Mn} L_{3}$ white line for each compound being reported in table I. The $\mathrm{Mn}^{\mathrm{II}}$ standards present a very narrow $L_{3}$ white line $(2.7 \mathrm{eV} \mathrm{FWHM})$ which shows also two shoulders at 1.5 and $3.6 \mathrm{eV}$ from the top of the main feature whereas the $L_{3}$ edges recorded on the other compounds present a broader shape ( $3.9 \mathrm{eV} \mathrm{FWHM)}$ these differences being attributed 


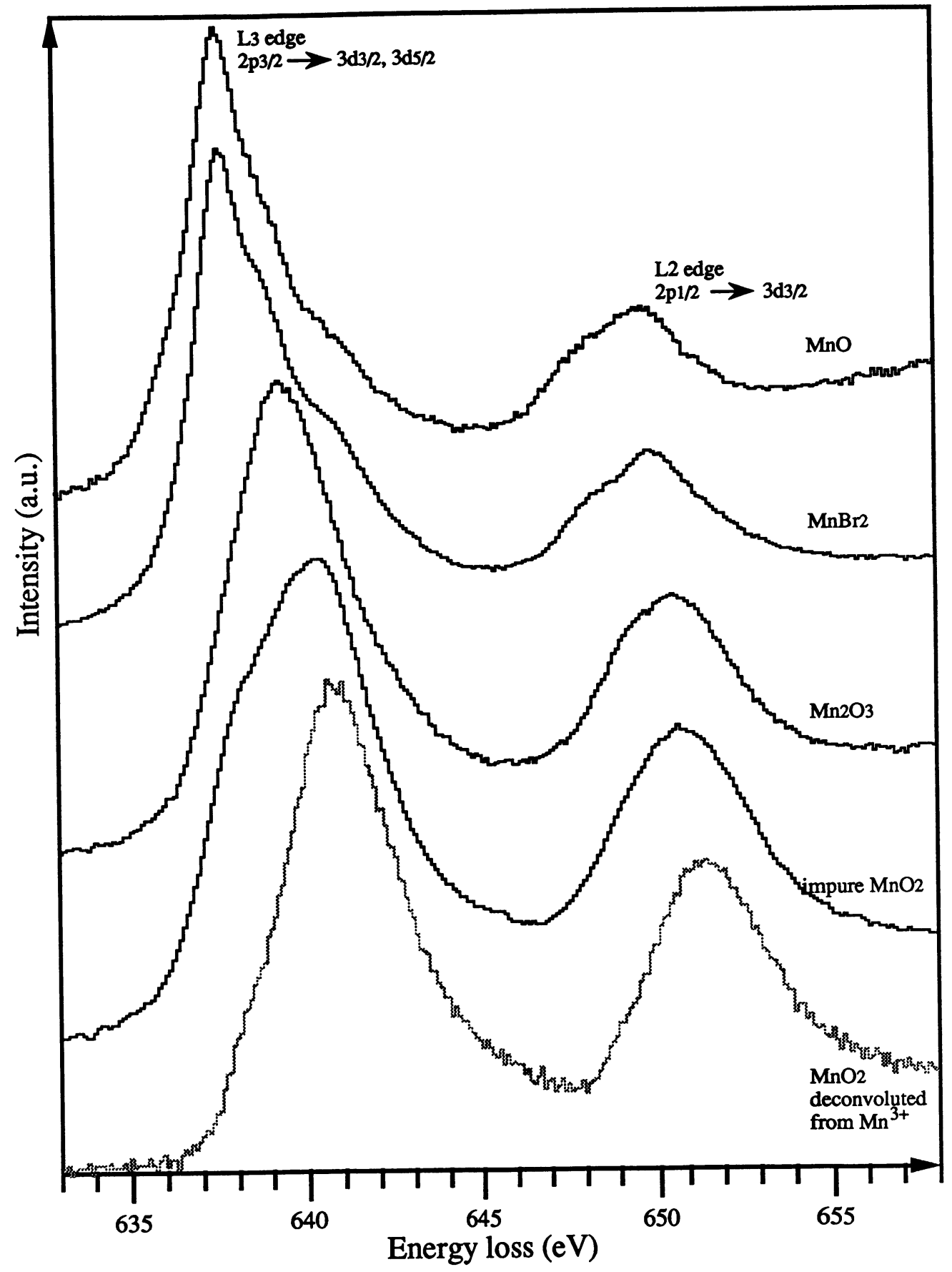

Fig. 2. $-L_{2,3}$ edges of manganese recorded on standard compounds, respectively $\mathrm{MnO}, \mathrm{MnBr}_{2}, \mathrm{Mn}_{2} \mathrm{O}_{3}$ and $\mathrm{MnO}_{2}$. In dotted line, the $\mathrm{Mn} L_{2,3}$ edges of $\mathrm{MnO}_{2}$ deconvoluted from $\mathrm{Mn}^{3+}$ species. 
to the fundamental electronic state of manganese in each structure [9]. In the case of $\mathrm{MnO}_{2}$, the $L_{3}$ edge presents a pre-edge shoulder which is attributed to the presence of $\mathrm{Mn}^{3+}$ in the standard possibly due to a partial reduction of the compound under electron irradiation. In order to confirm this last fact, the stoichiometry of the three standard oxides was checked by EELS quantitative analyses (using ELP software) on $\mathrm{Mn} L_{2,3}$ and $\mathrm{O} \mathrm{K}$ edges. The quantitative results effectively reveal that only the $\mathrm{MnO}_{2}$ standard presents a large deficiency of oxygen leading to a mean composition " $\mathrm{MnO}_{1.8}$ ".

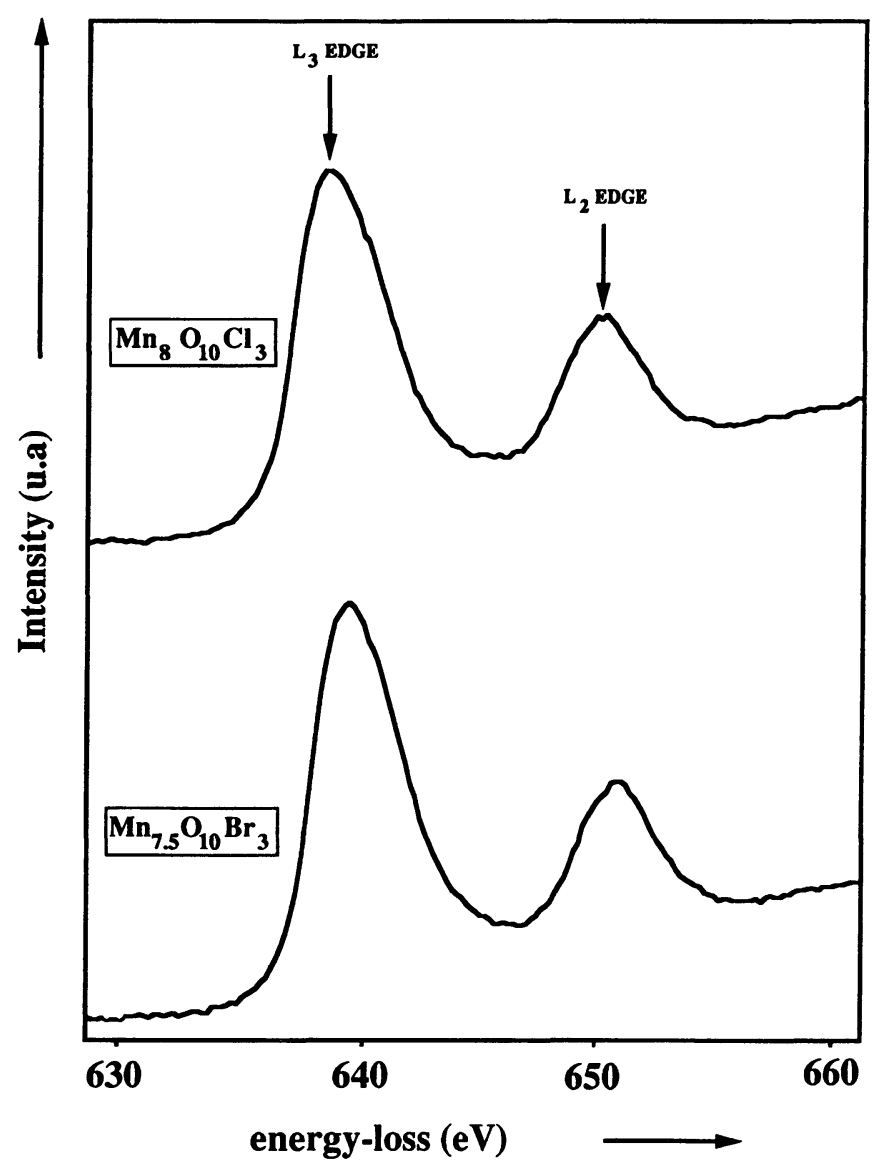

Fig. 3. - $\mathrm{Mn} L_{2,3}$ edges recorded on standard $\mathrm{Mn}_{8} \mathrm{O}_{10} \mathrm{Cl}_{3}$ and $\mathrm{Mn}_{7.5} \mathrm{O}_{10-\delta} \mathrm{Br}_{3}$.

In order to establish the real energy shift due to $\mathrm{Mn}^{4+}$ the spectra recorded on " $\mathrm{MnO}_{1,8}$ " were deconvoluted from $\mathrm{Mn}^{3+}$ and $\mathrm{Mn}^{2+}$ contributions using the calibrated experimental spectra of $\mathrm{MnO}$ and $\mathrm{Mn}_{2} \mathrm{O}_{3}$ standards (Fig. 2).

The $L_{2,3}$ edges of $\mathrm{Mn}_{8} \mathrm{O}_{10} \mathrm{Cl}_{3}$ and $\mathrm{Mn}_{7.5} \mathrm{O}_{10-\delta} \mathrm{Br}_{3}$ also display intense white lines. The presence of various ionisation states of manganese is not revealed by the existence of additional shoulders as it has been seen in other compounds $[12,13]$, the absence of such features being attributed to the small amount of $\mathrm{Mn}^{2+}$ and $\mathrm{Mn}^{4+}$ ions in the studied compounds. 


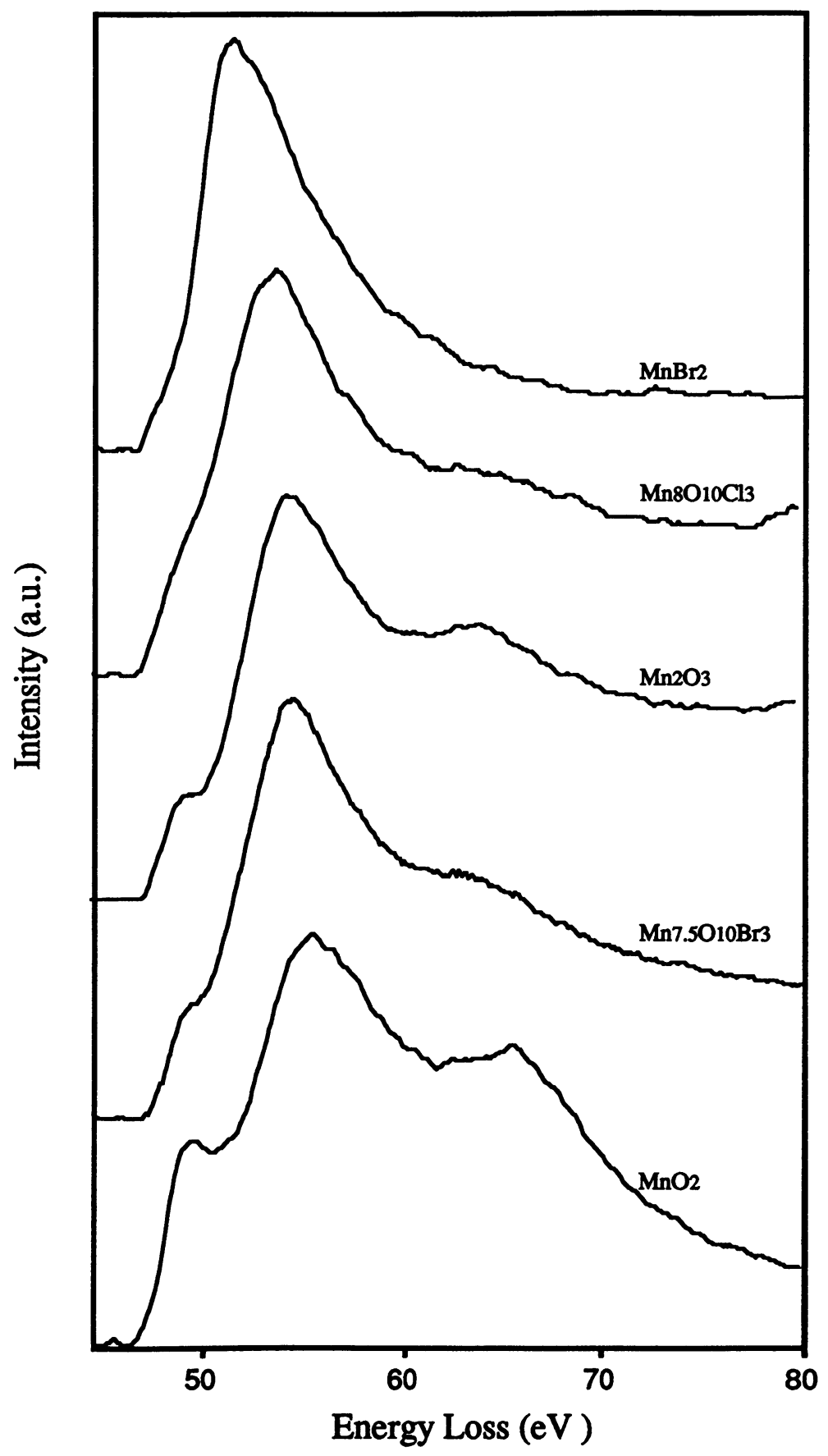

Fig. 4. $-\mathrm{Mn} \mathrm{M}_{2,3}$ edges recorded on the four standards $\left(\mathrm{MnBr}_{2}, \mathrm{Mn}_{2} \mathrm{O}_{3}\right.$, impure $\left.\mathrm{MnO}_{2}, \mathrm{Mn}_{8} \mathrm{O}_{10} \mathrm{Cl}_{3}\right)$ and on the unknown phase $\mathrm{Mn}_{7.5} \mathrm{O}_{10-\delta} \mathrm{Br}_{3}$. 
Mn $M_{2,3}$ edges recorded on the various compounds are presented in figure 4 . As it can be seen, the shape of the edge is very sensitive to the ionisation state. In the case of $\mathrm{MnBr}_{2}$, the main feature has a saw-tooth shape [10] preceeded by a weak shoulder. This pre-edge feature increases as a function of the valence state of manganese. In a first approximation based on the intensity of this pre-edge shoulder, $\mathrm{Mn}_{8} \mathrm{O}_{10} \mathrm{Cl}_{3}$ presents a $\mathrm{Mn}$ valence state less than 3 (as predicted by the formula) whereas $\mathrm{Mn}_{7.5} \mathrm{O}_{10} \mathrm{Br}_{3}$ seems to have a $\mathrm{Mn}$ mean valence close to that of $\mathrm{Mn}_{2} \mathrm{O}_{3}$ (very similar shape of the edges).

The energy position of both $L_{2,3}$ and $M_{2,3}$ edges as a function of the formal oxidation states of manganese are reported in figures 5 and 6. In the two curves, the " $\mathrm{MnO}_{2}$ standard" corresponds to the mean valence state 3.6 deduced from the quantitative analyses. Only in the case of the $L_{2,3}$ edges the $\mathrm{Mn}^{4+}$ energy shift obtained after deconvolution from $\mathrm{Mn}^{3+}$ and $\mathrm{Mn}^{2+}$ contributions is also reported.

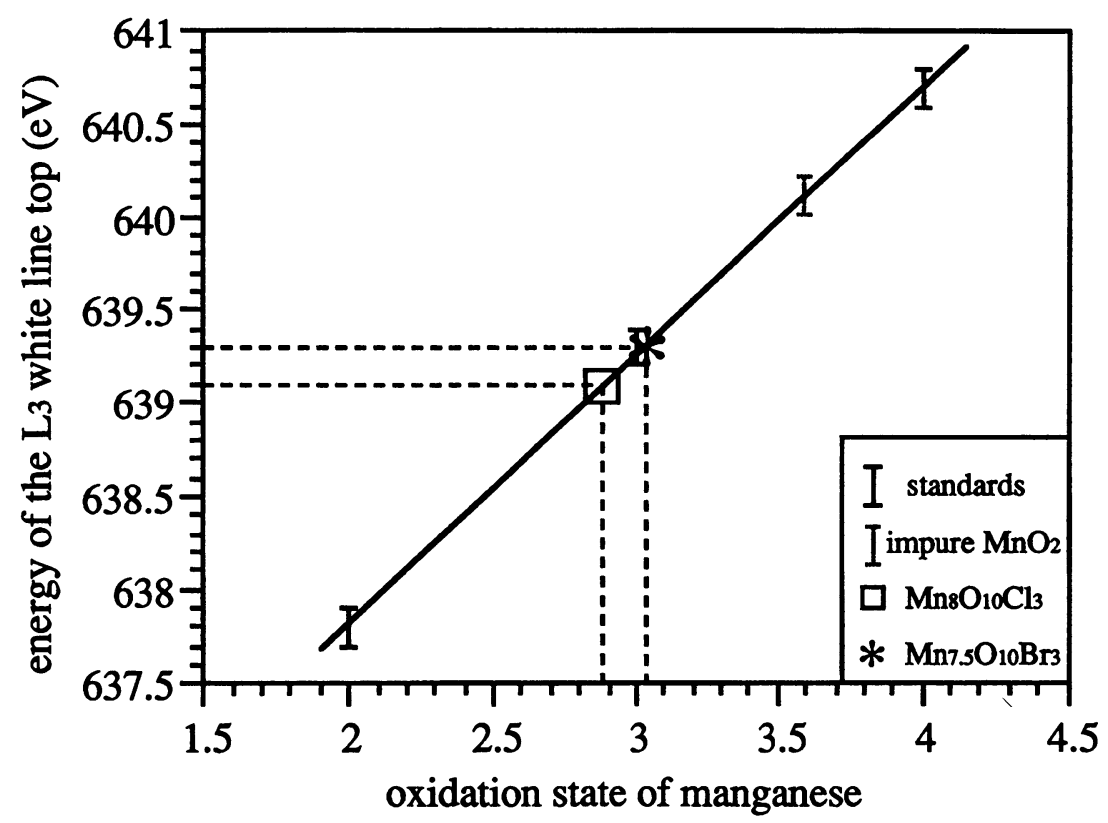

Fig. 5. - Experimental curve showing the evolution of the $\mathrm{Mn} L_{3}$ energy as a function of Mn oxidation state.

As it can be seen, in the two cases the edge energy position is a linear function of the oxidation state. For $M_{2,3}$ edges the slope is $2.7 \pm 0.3 \mathrm{eV}$ per oxidation degree and for $L_{2,3}$ edges $1.5 \pm 0.1 \mathrm{eV}$ per oxidation degree.

Figure 7 presents the evolution of the $L_{3} / L_{2}$ white line ratio as a function of oxidation state for the various standard compounds. The results obtained are in agreement with those obtained by Miner and Rask [5], Kurata and Colliex [11] but the precision is extremely poor.

The $L_{3}$ and $M 2,3$ energy shifts and $L_{3} / L_{2}$ intensity ratios measured on $\mathrm{Mn}_{8} \mathrm{O}_{10} \mathrm{Cl}_{3}$ and on the unknown compound $\mathrm{Mn}_{7.5} \mathrm{O}_{10-\delta} \mathrm{Br}_{3}$ are reported in the figures 5, 6 and 7 . 


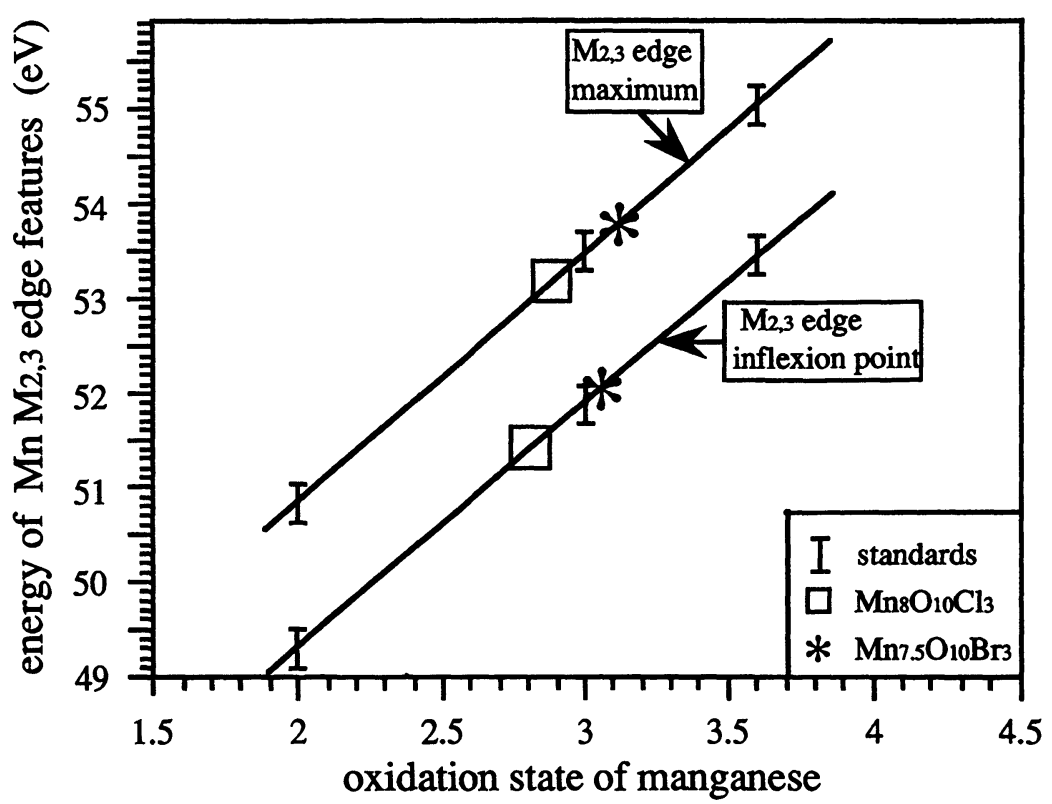

Fig. 6. - Evolution of the energy of $\mathrm{Mn} M_{2,3}$ edge features as a function of Mn oxidation state.

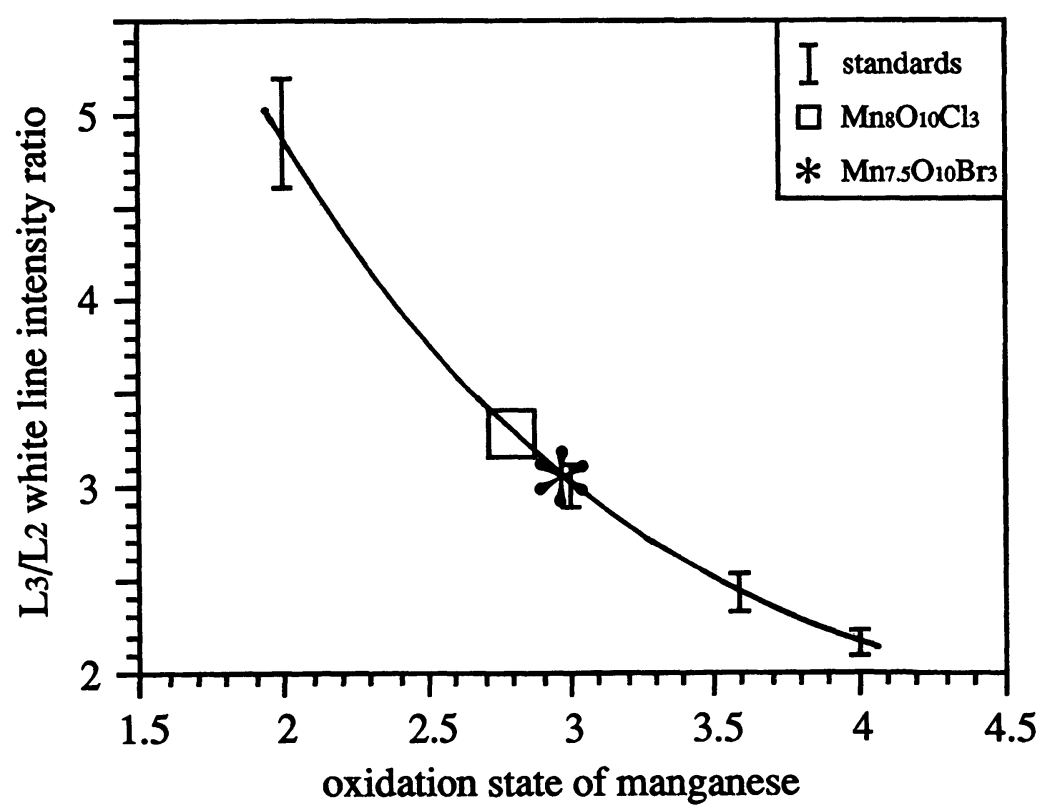

Fig. 7. - Variation of the $\mathrm{Mn} L_{3} / L_{2}$ white line intensity ratio as a function of $\mathrm{Mn}$ oxidation state. 
The mean oxidation states deduced for $\mathrm{Mn}_{8} \mathrm{O}_{10} \mathrm{Cl}_{3}$ from the $L_{2,3}$ and $M_{2,3}$ edges are respectively

$$
\begin{array}{cl}
L_{3} & V=2.86 \pm 0.06 \\
M_{2,3} \text { top } & V=2.9 \pm 0.1 \\
M_{2,3} \text { inflexion point } & V=2.8 \pm 0.1 \\
L_{3} / L_{2} \text { ratio } & V=2.8 \pm 0.2
\end{array}
$$

These results are in excellent agreement with the real mean oxidation state of 2.875 deduced from the formula. As can be seen, the best precision on the value is obtained when the energy shifts of the $L_{3}$ or $M_{2,3}$ edges are used. The large uncertainty of the $L_{3} / L_{2}$ ratios method is attributed both to the experimental error in the evaluation of $L_{3}$ and $L_{2}$ white line intensities and to the flattening of the curve for oxidation states lying in the range $2.5-4$.

In the case of $\mathrm{Mn}_{7.5} \mathrm{O}_{10-\delta} \mathrm{Br}_{3}$, the mean manganese oxidation states deduced from the three approaches are respectively

$$
\begin{array}{cl}
L_{3} & V=3.04 \pm 0.06 \\
M_{2,3} \text { top } & V=3.1 \pm 0.1 \\
M_{2,3} \text { inflextion point } & V=3.1 \pm 0.1 \\
L_{3} / L_{2} \text { ratio } & V=3.0 \pm 0.2
\end{array}
$$

The fact that the Mn mean oxidation state is found slightly greater than 3 points out the presence of $\mathrm{Mn}^{4+}$ in the compound which eliminate the $\mathrm{Mn}_{0.5}^{2+} \mathrm{Mn}_{7}^{3+} \mathrm{O}_{9.5} \mathrm{Br}_{3}$ formulation. This result is in agreement with structural determination, the hypothesis of oxygen vacancies had been tested without any positive results.

In the two last hypotheses, $\mathrm{Mn}_{0.5}^{4+} \mathrm{Mn}_{7}^{3+} \mathrm{O}_{10} \mathrm{Br}_{3}$ and $\mathrm{Mn}^{4+} \mathrm{Mn}_{6}^{3+} \mathrm{Mn}_{0.5}^{2+} \mathrm{O}_{10} \mathrm{Br}_{3}$ respectively, the calculated mean Manganese oxidation state of 3.067 is in good agreement with the experimental values deduced from EELS experiments (around 3.1). However it does not allow us to dismiss one of the two formulations.

In order to attempt to confirm one of the two hypothesis, we try a reconstruction of the $\mathrm{Mn} L_{2,3}$ edges features (white lines) recorded on $\mathrm{Mn}_{7.5} \mathrm{O}_{10} \mathrm{Br}_{3}$ using calibrated and normalized spectra of $\mathrm{MnO}, \mathrm{Mn}_{2} \mathrm{O}_{3}$ and $\mathrm{MnO}_{2}$. The used method is a linear combination of the edges of the three standards assuming that only single scattering events occur (which is all the more true considering that the thicknesses of the specimens are less than $200 \AA$ ) and that, at the level of the white lines features, the multiple scattering of ejected electron (ELNES//XANES) due to local order has a negligible contribution.

The linear combinations of $\mathrm{Mn}^{2+}, \mathrm{Mn}^{3+}$ and $\mathrm{Mn}^{4+} L_{2,3}$ edges in the case of the two hypothesis, $\mathrm{Mn}_{0.5}^{2+} \mathrm{Mn}_{6}^{3+} \mathrm{Mn}_{1}^{4+} \mathrm{O}_{10} \mathrm{Br}_{3}$ and $\mathrm{Mn}_{7}^{3+} \mathrm{Mn}_{0.5}^{4+} \mathrm{O}_{10} \mathrm{Br}_{3}$, are presented in figure 8 and compared to the experimental edges recorded on $\mathrm{Mn}_{7.5} \mathrm{O}_{10} \mathrm{Br}_{3}$. As can be seen the top of the white lines is in exact coincidence in the three cases and only a significant change in the white line width can be noted. The best agreement with the experimental $\mathrm{Mn}_{7.5} \mathrm{O}_{10} \mathrm{Br}_{3}$ spectrum is obtained in the case of the linear combination corresponding to the $\mathrm{Mn}_{0.5}^{2+} \mathrm{Mn}_{6}^{3+} \mathrm{Mn}_{1}^{4+} \mathrm{O}_{10} \mathrm{Br}_{3}$ formulation.

\section{Conclusion.}

In order to deduce the real formula of a manganese mixte valence compound EELS was used to investigate the mean oxidation state of manganese. Three features are used to reach this goal: energy shifts of the $L_{2,3}$ and $M_{2,3}$ edges and $L_{3} / L_{2}$ white line intensities ratios. The test of these three approaches on a well known compound demonstrates the validity of the method and points out the poor precision of the $L_{3} / L_{2}$ ratio approach, this last one being due both to the experimental errors during the evaluation of the white line intensities and the flattening of the curve $L_{3} / L_{2}$ 


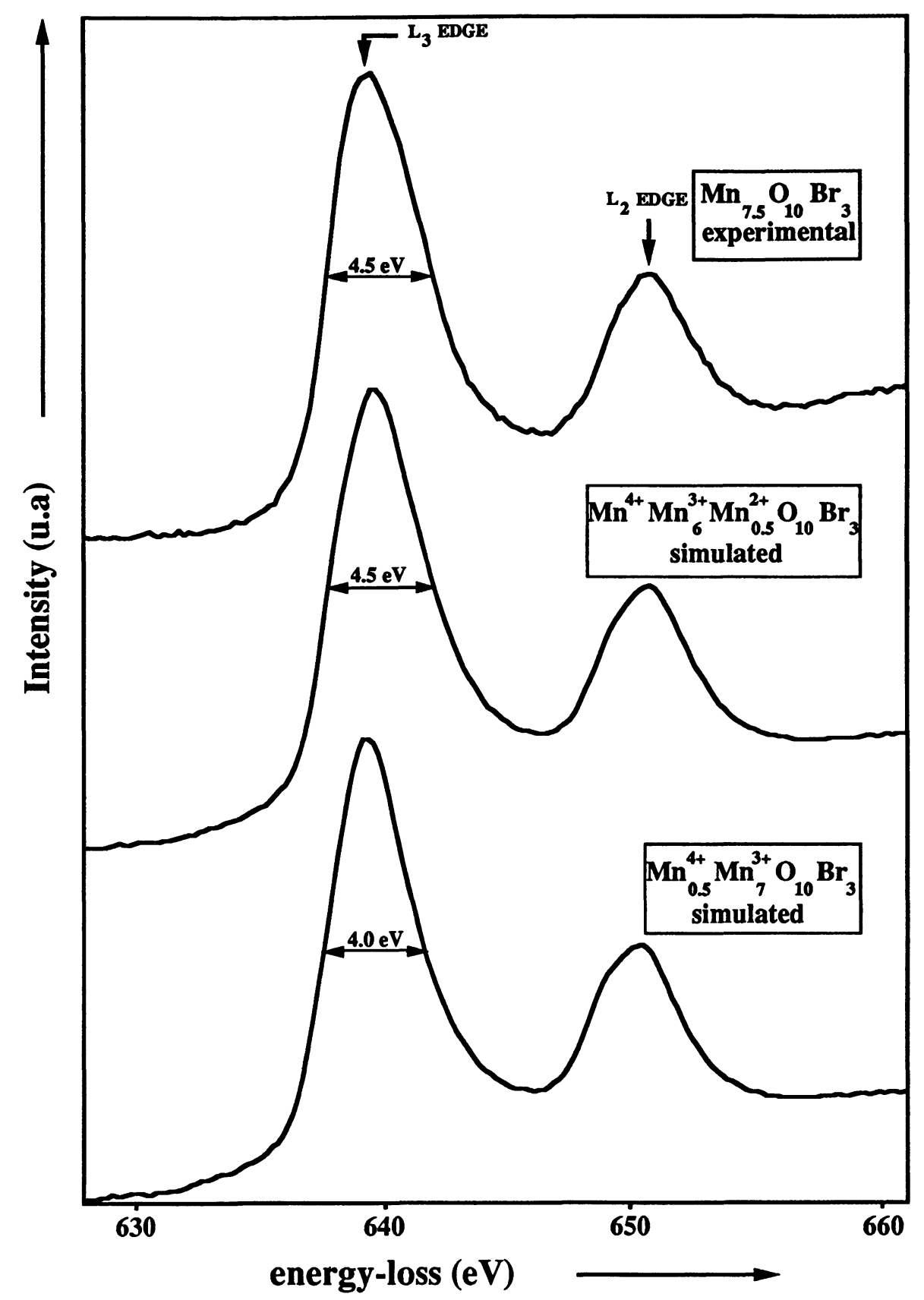

Fig. 8. - Comparison between experimental and reconstructed $\mathrm{Mn} L_{2,3}$ edges.

in the valence range $2.5-4$. The energy shifts of the $L_{3}$ and $M_{2}, 3$ edges as a function of oxidation state are linear and the great precision of the energy position of the edge features obtained with our experimental procedure allows us to minimize experimental errors.

The mean oxidation state of manganese, deduced from these last approaches, in the case of the oxybromide compounds allows us to dismiss the hypothesis where $\mathrm{Mn}^{4+}$ is absent. 
In order to determine the real formulation of the compound, we modelled, by linear combination of normalized $L_{2,3}$ edges obtained from the standard oxides, the $L_{2,3}$ edges of the oxybromide. The best agreement from this procedure is obtained for $\mathrm{Mn}_{0.5}^{2+} \mathrm{Mn}_{6}^{3+} \mathrm{Mn}_{1}^{4+} \mathrm{O}_{10} \mathrm{Br}_{3}$ which seems to eliminate the other hypothesis.

\section{References}

[1] Euzen P., Léone P., Mansot J.L., Bonneau P., Palvadeau P., Queignec M., Mat. Res. Bull. 27 (1992) 1423- 1430.

[2] Egerton R.F., "EELS in the Electron Microscope" (Plenum Press, New-York, 1986).

[3] Brown M., Peierls R.E. and Stern E.A., Phys. Rev. B15 (1977) 738.

[4] Leapman R.D., Grunes L.A. and Feyes P.L., Phys. Rev. B26 (1982) 614.

[5] Ahn C.C. and Krivanek O.L., "EELS Atlas", ASU HREM Facility Tempe and Gatan, Inc., Pleasanton (1983).

[6] Sparrow T.G., Williams B.G., Rao C.N.R. and Thomas J.M., Chem. Phys. Lett. 108 (1984) 547.

[7] Waddington W.B., Rez P., Grant J.P. and Humphreys C.J., Phys. Rev. B34 (1986) 1467.

[8] Euzen P., Léone P., Palvadeau P., Queignec M., Rouxel J., Mat. Res. Bull. 27 (1992) 1295-1300.

[9] Thole B.T., Cowan R.D., Sawatzky G.A., Fink J. and Fuggle J.C., Phys. Rev. B31 (1985) 6856.

[10] Colliex C., Manoubi T., Gasnier M. and Brown L.M., Scanning Electron Microscopy II (1985) 489-512.

[11] Kurata H. and Colliex C., Phys. Rev. B48 (1993) 2102-2108. 